\title{
Maternal and Fetal Outcomes in Pregnant Women With Polyhydramnios Treated Based on Maternal and Fetal Distress and Preterm Delivery
}

\author{
Zahra Fardiazar $^{1 *}$, Leila Soltanpour $^{1}$, Fatemeh Ghatrehsamani ${ }^{1}$
}

\begin{abstract}
Objectives: Polyhydramnios is a condition that could be along with significant maternal, fetal and neonatal consequences. One of the most important complications of this condition is preterm labor and delivery of preterm neonates. Although in mild cases expectant conservative management is effective, in more severe cases, medications (such as indomethacin) and amnioreduction could be considered. Each one of these methods could be accompanied with complications. This study aims to examine the results of management of patients with polyhydramnios according to the fetal and maternal distress and preterm labor criteria.

Materials and Methods: In this descriptive-analytic setting, 26 pregnant mothers with polyhydramnios (amniotic fluid index [AFI] more than 30) were managed according to the fetal and maternal distress and preterm labor criteria. In cases under 32 gestational weeks, indomethacin was used with an initial dose of $25 \mathrm{mg}$ every 6 hours and a maximum dose of $2-3 \mathrm{mg} / \mathrm{kg}$ that was tapered when the AFI diminished. In refractory cases, the flowchart of fetal and maternal distress and preterm labor was employed. In pregnancies aged over 32 weeks, in case of maternal distress amnioreduction was performed, and in asymptomatic patients, cervical length, funneling, color Doppler and placental thickness were evaluated and in normal cases controlling was carried every 1-2 weeks and abnormal cases amnioreduction was carried out.

Results: The mean age of studies patients was $28.12 \pm 7.22$ years and the mean pregnancy age was $232.23 \pm 23.57$ days. On this basis, there were 8 patients under 32 gestational weeks, in which indomethacin was administered and a response to treatment was seen in the week 1 . All cases have increased amniotic fluid again in week 2 . In 2 cases, re-administration was done. All patients including those aged over 32 weeks and those who reached 32 weeks by using indomethacin were managed according to the suggested algorithm. Symptoms indicating maternal distress was present in 3 patients (11.5\%), 2 of them were treated with amnioreduction and the other one did not give consent and pregnancy termination was carried out at the age of 29 gestational weeks due to cord prolapse. In 2 cases with amnioreduction, the pregnancy reached to term. The mean cervical length was $32.38 \pm 2.38 \mathrm{~mm}$ and dilatation or funneling was not present. Decreased placental thickness, placental malfunction and abnormal placental circulation were not detected. Except for the one mentioned case, all pregnancies were terminated over 34 gestational weeks, and besides a case with prolapse, no other maternal, fetal or neonatal complication was observed.

Conclusion: The effect of indomethacin was temporary and this medication could be used safely. The beginning of delivery is suddenly in these patients and is not predictable by cervical changes. The placenta was normal in all cases in the current study. In case of maternal distress, amnioreduction was along with good outcome. Color Doppler evaluation and placental thickness were not accompanied with good results.

Keywords: Polyhydramnios, Indomethacin, Amnioreduction
\end{abstract}

\section{Introduction}

Polyhydramnios is a medical condition describing an excess of amniotic fluid in the amniotic sac which can be seen in $1 \%-2 \%$ of women. The overall prevalence of this condition is reported on 750 pregnancies. Patients suffered from polyhydramnios often referred to hospitals complaining about discomfort in the abdomen and respiratory distress. Abnormal magnitude of the uterus (compared to gestational age) along with difficulty touching embryonic organs and problems associated with fetus auscultation can be observed on physical examination. A definitive diagnosis is ultimately possible through ultrasound and by measuring the ammonic fluid index. Amniotic fluid index (AFI) more than $25 \mathrm{~cm}$ is considered as polyhydramnios, accordingly (1).
Polyhydramnios may be associated with fetal and maternal complications such as respiratory distress, thromboembolism, preterm labor, atonic uterus, anemia, caesarean section, premature fetus, umbilical cord prolapse caused by the rupture of the membranes and fetal distress (2-4).

Common treatment methods of polyhydramnios pregnancies include examination of maternal risk factors (diabetes, viral hepatitis, syphilis and other torch infections and addiction) and examination of fetal risk factors (hydrops fetalis, esophageal atresia, gastroschisis, anencephaly, diaphragmatic hernia, placental chorioangioma, severe anemia, heart problems and chromosomal abnormalities). In mild cases, simple control and follow-ups, continuous ultrasound and conservative treatment methods 
are recommended (5). In idiopathic cases, administration of indomethacin at a dose of $1.5 \mathrm{mg}$ per body weight per day for 1 week is prescribed for pregnancies less than 32 weeks (6).

Ultrasound is still a useful diagnostic and follow-up modality in these patients. Some studies have shown that cervix funneling and cervix shortening observed during ultrasonography could indicate preterm labor. Nevertheless, results have been contradictory in this matter (7-9).

One of the proposed solutions to prevent preterm birth in these patients is amnioreduction (draining amniotic fluid through a needle inserted through the mother's abdominal skin). This approach is currently being carried out only in case of maternal indications, shortness of breath and tightness (10).

In this study, we are intended to conduct the intervention using fetal symptoms (including enlarged uterus pressing on the cervix which causes preterm delivery) in addition to maternal symptoms based on the measurement of cervical length and cervix funneling. Moreover, by examining the uterine-placental blood flow and thickness of the placenta through ultrasound, we are going to predict fetal distress and make decisions based on obtained algorithm.

\section{Materials and Methods}

The descriptive cross-sectional study investigated 26 pregnant women suffered from polyhydramnios at high-risk pregnancy clinic of Alzahra University hospital of Tabriz based on maternal and fetal distress and preterm birth from March 21, 2015 to April 20, 2016.

During the study, its goals, advantages and probable consequences were explained in detail to the patients and intervention was carried out after obtaining written consent from the patient and his spouse.

The inclusion criteria included a full medical record, consent of the patient, gestation age of 24 to 37 weeks, diagnosis of polyhydramnios by ultrasound, showing fetal anomaly by ultrasound and singleton pregnancy.

In pregnancies under 32 weeks, the treatment with in- domethacin was commenced at $25 \mathrm{mg}$ every 6 hours and increased to the maximum dose of $2-3 \mathrm{mg} / \mathrm{kg}$ (200 mg). In the meantime, AFI was measured once a week and in case of decrease in the index indomethacin was gradually cut out. All pregnancies above 32 weeks and patients who had been under indomethacin and reached week 32 were managed with the proposed algorithm (see Figure 1).

\section{Statistical analysis}

Collected data were analyzed by SPSS 16.0 and expressed in form of standard deviation, mean, median and frequency (percentage). Mann-Whitney U test were applied to compare quantitative data and chi-square and Fisher exact test were employed to compare qualitative data. The correlation between variables was examined using Pearson correlation. $P \leq 0.05$ was considered statistically significant.

\section{Results}

Twenty-six patients with idiopathic polyhydramnios with the index above 30 were studied prospectively at Al-Zahra hospital. In all cases, patients were referred to the hospital based on ultrasound's results during conventional prenatal check-ups so none of them were admitted due to maternal distress.

The mean age of patients was $28.12 \pm 7.22$ years (17-42). Twenty-one patients $(80.8 \%)$ lived in urban areas while 5 patients (19.2\%) resided in rural areas. The mean gestational age of participants was $232.23 \pm 23.57$ days (184273) at the time of the study. Given this, the gestational age in 8 patients was less than 32 weeks and the others were 32 weeks and above. Average gravidity and parity were $1.58 \pm$ 0.81 (1-4) and $0.62 \pm 0.14$ (1-4), respectively. Up to 200 $\mathrm{mg}$ of indomethacin was prescribed for average period of $1.38 \pm 0.74$ for 8 patients who had gestational age of less than 32 weeks ( 6 cases, 1 period, 1 case, 2 periods and 1 case, 3 periods). The interim response to indomethacin was observed in all 8 cases. Maternal distress symptoms were found in 3 patients (11.5\%) which two of them went

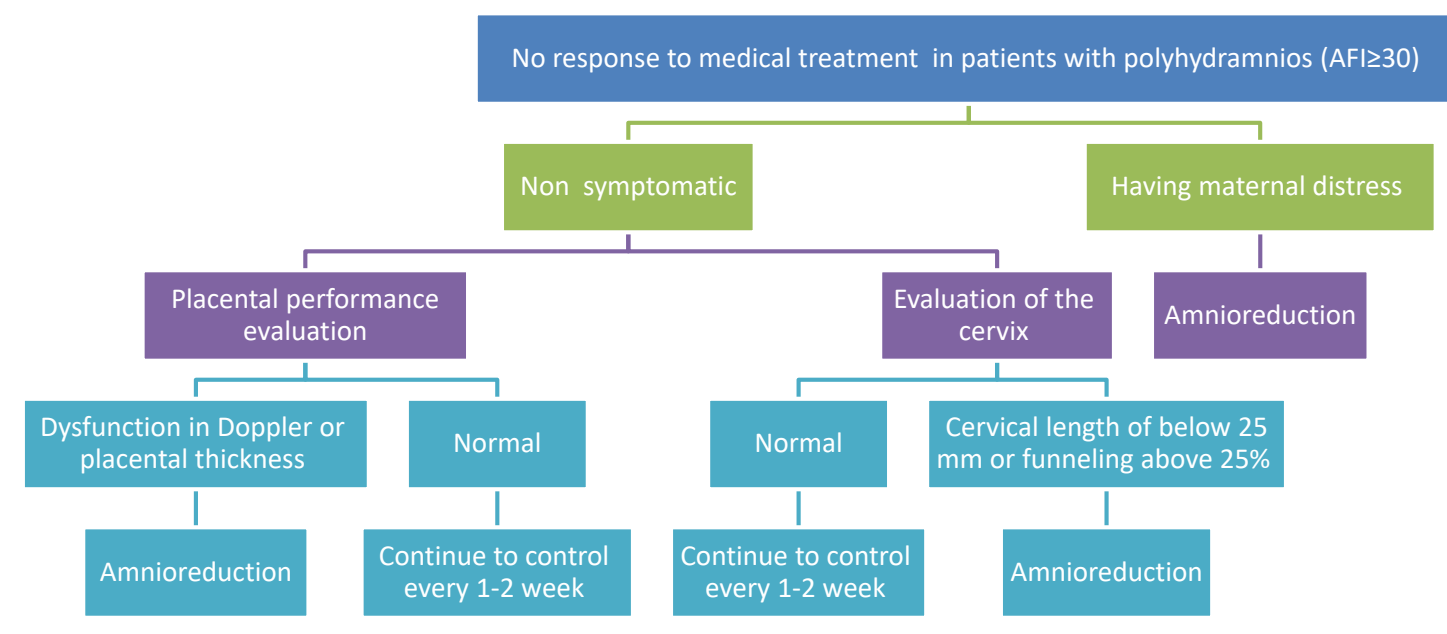

Figure 1. The Algorithm of Managing Patients in Case of Not Responding to the Drug. 
Table 1. Frequency, Percentage and Causes of Delivery in Studied Patients Based on Gestational Age

\begin{tabular}{|c|c|c|}
\hline \multirow[b]{2}{*}{ Termination of Pregnancy and Related Causes } & \multicolumn{2}{|c|}{ Gestational Age } \\
\hline & $\begin{array}{c}<32 \text { Weeks } \\
\text { No. (\%) }\end{array}$ & $\begin{array}{c}\geq 32 \text { Weeks } \\
\text { No. (\%) }\end{array}$ \\
\hline Cesarean section (CS) & $5(38.5)$ & $8(61.5)$ \\
\hline Vaginal delivery & $3(23.1)$ & $10(76.9)$ \\
\hline Previous CS and labor pain & $1(20)$ & $4(50)$ \\
\hline Umbilical cord prolapse & $2(40)$ & $0(0)$ \\
\hline Rupture of membrane (PROM) and meconium staining & $0(0)$ & $1(12.5)$ \\
\hline Labor pain and breech presentation & $0(0)$ & $1(12.5)$ \\
\hline Fetal hypoxia & $0(0)$ & $1(12.5)$ \\
\hline Previous cesarean and PROM & $1(20)$ & $0(0)$ \\
\hline previous CS at term & $0(0)$ & $1(12.5)$ \\
\hline Macrosomy at term & $1(20)$ & $0(0)$ \\
\hline Labor pain & $1(33.3)$ & $7(70)$ \\
\hline PROM & $2(66.7)$ & $3(30$ \\
\hline
\end{tabular}

under amnioreduction and one of them did not consent.

The average cervical length was $32.38 \pm 2.38 \mathrm{~mm}$ (3041). Dilatation or funneling had not seen in cases. According to Pearson correlation test, there was a significant inverse correlation between cervical length and gestational age $(r=0.40, P=0.05)$ while there was no correlation between cervical length and amniotic fluid index $(r=0.47$, $P=0.15)$.

Also, there was no sign of placental insufficiency in any of the participants. There was neither sign of reduction nor dysfunction of the placenta thickness in the color Doppler. Amnioreduction was conducted in 2 patients $(7.7 \%)$. The average index of amniotic fluid was determined to be $32.2 \pm 2.46$ (30-41). Thirteen patients had spontaneous vaginal delivery $(50 \%)$ while 13 patients were given C-section (50\%). The average Apgar scores were 8.96 \pm 0.20 $(8,9)$ and $9.96 \pm 0.20(9-10)$ in the first and fifth minutes, respectively. One patient was subjected to cord prolapse $(8.1 \%)$ and there was no fetal anomaly. The mean age of pregnancy termination was $254.04 \pm 11.78$ (203-266). All pregnancies (except for one case that did not consent to amnioreduction) ended over 34 weeks.

The causes of previous termination of pregnancy were categorized according to type of delivery and gestational age and summarized in Table 1.

Study variables were compared and summarized by gestational age of less than 32 weeks and 32 weeks and above in Table 2.

It was ultimately concluded that there was no statistically significant difference between the two groups in terms of maternal age, location of residence, gravidity, parity, maternal distress, amnioreduction, type of delivery, Apgar score at first and fifth minutes, prolapse and age of termination of pregnancy. The median of AFI in patients with gestational age of below 32 weeks was significantly greater ( 32 vs. $31, P=0.04$ ). It should be noted that in this group and following the administration of indomethacin, AFI decreased to below 30 in 7 patients and did not change in 1 patient in the first week ultrasound. However, amniotic
Table 2. The Comparison of Study Variables in Patients With Gestational Age of Less Than 32 Weeks and 32 Weeks and Above

\begin{tabular}{|c|c|c|c|}
\hline \multirow[b]{2}{*}{ Variable } & \multicolumn{2}{|c|}{ Gestational Age } & \multirow[b]{2}{*}{$P$ Value } \\
\hline & $\begin{array}{l}<32 \text { Weeks } \\
\text { (8 Patients) }\end{array}$ & $\begin{array}{c}\geq 32 \text { Weeks } \\
\text { (18 Patients) }\end{array}$ & \\
\hline Age & 27 & 29 & 0.57 \\
\hline \multicolumn{4}{|l|}{ Location of residence } \\
\hline City & $5(62.5)$ & $16(88.9)$ & 0.28 \\
\hline Rural areas & $3(37.5)$ & $5(19.2)$ & \\
\hline Gravidity & 1 & 1 & 0.89 \\
\hline Parity & 0 & 1 & 0.57 \\
\hline AFI & 32 & 31 & $0.04^{*}$ \\
\hline Cervical length (cm) & 33 & 31.5 & $0.04^{*}$ \\
\hline Amnioreduction & $2(25)$ & $0(0)$ & 0.09 \\
\hline \multicolumn{4}{|l|}{ Type of delivery } \\
\hline Vaginal & $3(37.5)$ & $10(55.6)$ & 0.67 \\
\hline Cesarean section & $5(62.5)$ & $8(44.4)$ & \\
\hline \multicolumn{4}{|l|}{ Apgar } \\
\hline At 1st Min & 9 & 9 & 0.85 \\
\hline At 5th Min & 10 & 10 & 0.85 \\
\hline Prolapse & $1(12.5)$ & $0(0)$ & 0.31 \\
\hline $\begin{array}{l}\text { Age of termination of } \\
\text { pregnancy }\end{array}$ & 254.5 & 256.5 & 0.94 \\
\hline
\end{tabular}

fluid raised again during the second week. In the second week sonogram and following the administration of indomethacin, all 8 patients demonstrated AFI increase above 30 .

Two of 8 patients were given once more indomethacin while others (those with gestational age of above 32 weeks) did not receive it. The median of cervical length in those with gestational age of below 32 weeks was also significantly higher ( 33 vs. $31.5 \mathrm{~cm}, P=0.01$ ).

It should be stated that among the patients with gestational age of below 32 weeks, amnioreduction procedure was carried out 3 times in one patient and 2 times in the other. One patient was offered amnioreduction due to respiratory distress but she refused so she underwent emer- 
gency cesarean section at 29 weeks due to umbilical cord prolapse.

\section{Discussion}

The study examined maternal and fetal outcomes in pregnant women suffered from polyhydramnios and treated based on maternal-fetal distress and preterm delivery.

A total of 26 patients with idiopathic polyhydramnios with AFI of above 30 were investigated. $30.8 \%$ had gestational age of below 32 and went under indomethacin medication. The results showed that the indomethacin temporarily led to reduction of amniotic fluid and that it raised again in two weeks.

Although prostaglandin synthesis inhibitors such as indomethacin are used in the management of patients with polyhydramnios for several years, drawing conclusions in this area is very difficult

due to conflicting evidences. Much of these contradictions can be attributed to the overwhelming outdated literature exist in this field.

In the study of Kirshon et al (11), administration of indomethacin in 8 pregnant women suffered from symptomatic polyhydramnios pregnancy with average gestational age of 28.6 weeks was examined. They found that only in 1 out 8 patients there was a need to amnioreduction. They also figured out that reduction of amniotic fluid showed significance after treatment with indomethacin and maternal-fetal complications were not reported. In line with the results of this study, we also concluded that there were no maternal, fetal or neonatal complications in indomethacin recipients. Seven out of 8 patients treated with indomethacin, showed AFI reduction to less than 30 in the first week of Ultrasonography and one showed no change at all. In the second week of ultrasonography and following the administration of indomethacin, all 8 patients demonstrated AFI increase above 30. Given the circumstances, 2 out of 8 were treated with indomethacin again while others (those with gestational age of above 32 weeks) did not receive it. However, none of the patients dosed with indomethacin required amnioreduction which is contrary to the work of Kirshon et al.

Although indomethacin is introduced as one the best tocolysis drugs that can delay delivery and manage idiopathic polyhydramnios, it may cause major complications such as kidney failure, necrotizing enterocolitis, intraventricular hemorrhage and closure of the ductus arteriosus (patent ductus arteriosus, in which there is a persistent communication between the descending thoracic aorta and the pulmonary artery that results from failure of normal physiologic closure of the fetal ductus. This patency is promoted by continual production of PGE2 by the ductus. Closure of the ductus before birth may lead to right heart failure. Prostaglandin antagonism, such as maternal use of nonsteroidal anti-inflammatory drugs (NSAIDs), can cause fetal closure od the ductus arteriosus.) (12).

The difference in the intensity of polyhydramnios, underlying diseases and anomalies along with the difference in the dose of prescribed indomethacin can all justify dif- ferent outcomes given by various studies.

Cabrol et al (6) examined 22 patients with polyhydramnios who underwent indomethacin medication at a dose of $3 \mathrm{mg}$ per kilogram of body weight per day. The average gestational age was 28.2 weeks at the beginning of the experiment and lasted until week 35 . Treatment outcomes were reported statistically significant and no major maternal and fetal complication was detected. However, there existed 3 cases of fetal death; two cases due to fetal anomalies and one because of cord entanglement (6). Contradictory to this study, none of our cases had fetal anomalies and that justify the lack of complications and mortality.

It should be noted that only one case of preterm delivery was seen in our study which belonged to a mother who refused to have amnioreduction due to distress. Therefore, pregnancy was terminated in emergency at week 29 .

In our study, there was no significant difference in terms of termination of pregnancy both in the recipient group and those who did not receive indomethacin (245.5 vs. 256.5).

One of the major complications associated with polyhydramnios is preterm delivery that in $20 \%$ of patients has been reported. It should be noted that this percentage is lower $(10 \%$ to $15 \%)$ in normal singleton pregnancies (13-15). As stated previously, there was no case of preterm delivery in our work.

The positive effect of reducing the volume of amniotic fluid in patients with polyhydramnios was highlighted previously in a study by Rodriguez (16). However, Many et al found that underlying causes of polyhydramnios and not the volume of amniotic fluid is a major factor associated with preterm delivery so that in idiopathic cases the risk of preterm birth has been less than cases with underlying causes of polyhydramnios (14).

Based on this issue, determining whether the correct and effective management of polyhydramnios in this study actually had an impact in the prevention of preterm birth or this has been caused by the inclusion of patients with idiopathic polyhydramnios, will require further controlled investigations (see recommendation section). Using color Doppler, no abnormalities were found in any of the patients in terms of placental thickness, function and circulation in our study.

Another study conducted by Hershkovitz et al (17) compared Doppler findings of the placenta and its circulation between two group of patients; 72 polyhydramnios positive patients between gestational ages of 26 to 41 weeks and 72 normal pregnant women. The study demonstrated no statistically significant difference (17).

In our study, we examine the cervix using intravaginal ultrasound which did not show any dilatation or funneling. Therefore, it seems that the start of delivery is unexpected and cervical length is not a prognostic factor in this context.

This finding is consistent with the results of other studies. For instance, a study done by Engineer et al (18) in twin pregnancies with polyhydramnios showed that cervical shortening is not an acute process and that short-term 
treatment do not have a significant impact on cervical length. Furthermore, we did not find a significant correlation between the severity of polyhydramnios (based on AFI) and cervical length and this is while cervical length was negatively correlated with gestational age.

In the study of Hershkovitz et al (7), the length of cervix was examined in patients with polyhydramnios. In this retrospective study, the cervical length of 92 patients with gestational ages from 24 to 40 weeks was measured by transvaginal ultrasound. The median of cervical length was reported $37.5 \mathrm{~mm}$. Similar to our study, there was not a significant relationship between AFI and cervical length so it was concluded that in these patients, although the gradual shortening of the cervix can be seen as pregnancy progresses, it is not related to polyhydramnios.

In normal pregnancies, as gestational age increases, gradual reduction of cervical length can be observed (1922). Similar to twin pregnancies, polyhydramnios can lead to shortening of the cervix with uterine distension (7). Why there is no significant correlation between cervical length and severity of polyhydramnios is unknown. Perhaps it can be attributed to existing mechanisms between cervical length and twin or multiple pregnancies with mechanisms exist between cervical length and polyhydramnios (7).

In the current study, amnioreduction indication was present in $11.5 \%$ of cases due to respiratory distress of the mother; one patient did not consent to do it and two others did not show major complications.

Dickinson et al (10) carried out 271 amnioreduction on 128 patients with polyhydramnios and investigated the results. The average gestational age at the time of this treatment was 31.4 weeks. The incidence of respiratory distress of the mother which made amnioreduction necessary, were reported $45.6 \%$. Finally, it was shown that the treatment has been successful with no maternal-fetal complications. Although similar, the incidence of respiratory distress in their study was higher than ours.

Amnioreduction complications in patients suffered from polyhydramnios were explored in a study by Kleine et al (23). Of 135 patients who were examined, 44 (32.6\%) had respiratory distress and subsequently required amnioreduction. Based on the findings of this study and in accordance with the findings of the current study, the procedure caused no major complications (23).

In conclusion, we showed in this study that the treatment procedure in patients with polyhydramnios was a total success and result in no maternal, fetal or neonatal complications. The results of the following studies in this field are contradictory:

Panting-Kemp (24) showed that idiopathic polyhydramnios did not increase maternal, fetal and neonatal.

Nevertheless, the study of Taskin et al (25) which examined prenatal outcomes in patients with idiopathic polyhydramnios (59 singleton pregnancies), indicated that the percentage of preterm delivery was higher and average Apgar score was lower in comparison with the control group.
Wiegand et al (26) also concluded that the incidence of maternal, fetal and neonatal complications is positively correlated with the severity of polyhydramnios.

So in order to obtain absolute results in this area, we are required to conduct further case-control studies and include patients with non-idiopathic polyhydramnios.

\section{Conclusion}

According to the findings of the study, administration of indomethacin can only temporarily reduce the amount of amniotic fluid in polyhydramnios cases. Since the fluid starts to increase again within two weeks, indomethacin can be considered as a tocolysis and used to decrease amniotic fluid in order to prevent maternal and neonatal risks especially in low gestation ages. There were no signs of cervical dilatation and funneling while examining the cervix. Thus, it seems that the start of delivery is unexpected and cervical length is not a prognostic factor in this context. Color Doppler also reported that the thickness and performance of the placenta were normal in all patients.

\section{Ethical Issues}

This study was approved by the Ethics Committee of Tabriz University of Medical Sciences.

\section{Conflict of Interests}

None.

\section{Financial Support}

This study supported by Women's Reproductive Health Research Center, Tabriz University of Medical Sciences, Tabriz, Iran.

\section{References}

1. Cunningham FG. Williams Obstetrics. 24th ed. New York: McGraw-Hill Medical; 2014.

2. Mathew M, Saquib S, Rizvi SG. Polyhydramnios. Risk factors and outcome. Saudi Med J. 2008;29(2):256-260.

3. Sandlin AT, Chauhan SP, Magann EF. Magann, Clinical relevance of sonographically estimated amniotic fluid volume: polyhydramnios. J Ultrasound Med. 2013;32(5):851-63. doi: 10.7863/ultra.32.5.851.

4. Thompson O, Brown R, Gunnarson G, Harrington K. Prevalence of polyhydramnios in the third trimester in a population screened by first and second trimester ultrasonography. J Perinat Med. 1998;26(5):371-377.

5. Crowther CA, Haslam RR, Hiller JE, Doyle LW, Robinson JS; Australasian Collaborative Trial of Repeat Doses of Steroids (ACTORDS) Study Group. Neonatal respiratory distress syndrome after repeat exposure to antenatal corticosteroids: a randomised controlled trial. Lancet. 2006;367(9526):1913-1919.

6. Cabrol D, Jannet D, Pannier E. Treatment of symptomatic polyhydramnios with indomethacin. Eur J Obstet Gynecol Reprod Biol. 1996;66(1):11-15.

7. Hershkovitz R, Sheiner E, Maymon E, Erez O, Mazor M. Cervical length assessment in women with idiopathic polyhydramnios. Ultrasound Obstet Gynecol. 2006 Nov;28(6):775-8. 
8. To MS, Skentou C, Liao AW, Cacho A, Nicolaides KH. Cervical length and funneling at 23 weeks of gestation in the prediction of spontaneous early preterm delivery. Ultrasound Obstet Gynecol. 2001;18(3):200-203.

9. Tsoi E, Geerts L, Jeffery B, Odendaal HJ, Nicolaides KH. Sonographic cervical length in threatened preterm labor in a South African population. Ultrasound Obstet Gynecol. 2004;24(6):644-646.

10. Dickinson JE, Tjioe YY, Jude E, Kirk D, Franke M, Nathan E. Amnioreduction in the management of polyhydramnios complicating singleton pregnancies. Am J Obstet Gynecol. 2014;211(4):434.e1-7. doi: 10.1016/j.ajog.2014.05.036.

11. Moise KJ Jr. Indomethacin therapy in the treatment of symptomatic polyhydramnios. Clin Obstet Gynecol. 1991;34(2):310-318.

12. Abou-Ghannam G, Usta IM, Nassar AH. Nassar, Indomethacin in pregnancy: applications and safety. Am J Perinatol. 2012;29(3):175-86. doi: 10.1055/s-0031-1284227.

13. Ananth CV, Joseph KS, Oyelese Y, Demissie K, Vintzileos AM. Trends in preterm birth and perinatal mortality among singletons: United States, 1989 through 2000. Obstet Gynecol. 2005;105(5 Pt 1):1084-1091.

14. Many A, Hill LM, Lazebnik N, Martin JG. The association between polyhydramnios and preterm delivery. Obstet Gynecol. 1995;86(3):389-391.

15. Mazor M, Ghezzi F, Maymon E, et al. Polyhydramnios is an independent risk factor for perinatal mortality and intrapartum morbidity in preterm delivery. Eur J Obstet Gynecol Reprod Biol. 1996;70(1):41-47.

16. Rodriguez MH. Polyhydramnios: does reducing the amniotic fluid volume decrease the incidence of prematurity? Clin Perinatol. 1992;19(2):359-366.

17. Hershkovitz R, Sheiner E, Furman B, Smolin A, Hallak M, Mazor M. Uterine artery Doppler velocimetry in patients with idiopathic hydramnios. Fetal Diagn Ther. 2002;17(1):48-51.

18. Engineer N, O’Donoghue $\mathrm{K}$, Wimalasundera RC, Fisk
NM. The effect of polyhydramnios on cervical length in twins: a controlled intervention study in complicated monochorionic pregnancies. PLoS One. 2008;3(12):e3834. doi:10.1371/journal.pone.0003834.

19. Fujita MM, Brizot Mde L, Liao AW, et al. Reference range for cervical length in twin pregnancies. Acta Obstet Gynecol Scand. 2002;81(9):856-9.

20. Goldenberg RL, Iams JD, Das A. The Preterm Prediction Study: sequential cervical length and fetal fibronectin testing for the prediction of spontaneous preterm birth. National Institute of Child Health and Human Development Maternal-Fetal Medicine Units Network. Am J Obstet Gynecol. 2000;182(3):636-643.

21. Hoesli IM, Strutas D, Tercanli S, Holzgreve W. Charts for cervical length in singleton pregnancy. Int J Gynaecol Obstet. 2003;82(2):161-165.

22. Azar ZF, Hakimi P, Ghojazadeh M, Ghatresamani F. Preand post-McDonald cerclage cervical length, width and funneling rate and their association with duration of pregnancy. Pak J Biol Sci. 2011;14: 502-506.

23. Kleine RT, Bernardes LS, Carvalho MA, de Carvalho MH, Krebs VL, Francisco RP. Pregnancy outcomes in severe polyhydramnios: no increase in risk in patients needing amnioreduction for maternal pain or respiratory distress. J Matern Fetal Neonatal Med. 2016;29(24):4031-4034. doi: 10.3109/14767058.2016.1153060.

24. Panting-Kemp A, Nguyen T, Chang E, Quillen E, Castro L. Idiopathic polyhydramnios and perinatal outcome. Am J Obstet Gynecol. 1999;181(5 Pt 1):1079-1082.

25. Taskin S, Pabuccu EG, Kanmaz AG, Kahraman K, Kurtay G. Perinatal outcomes of idiopathic polyhydramnios. Interv Med Appl Sci. 2013;5(1):21-25. doi: 10.1556/ IMAS.5.2013.1.4.

26. Wiegand SL, Beamon CJ, Chescheir NC, Stamilio D. Idiopathic polyhydramnios: severity and perinatal morbidity. Am J Perinatol. 2016;33(7):658-664. doi: 10.1055/s-0036-1571320.

Copyright $\odot 2017$ The Author (s); This is an open-access article distributed under the terms of the Creative Commons Attribution License (http://creativecommons.org/licenses/by/4.0), which permits unrestricted use, distribution, and reproduction in any medium, provided the original work is properly cited. 